\title{
STUDIES ON THE HEAT RECOVERY FROM THE SINTER COOLER, S.C. ARCELORMITTAL GALATI
}

\author{
Adrian VASILIU \\ "Dunarea de Jos" University of Galati, Faculty of Engineering \\ e-mail: avasiliu@ugal.ro
}

\begin{abstract}
Heat recovery to the sinter plant is a means of improving the efficiency of the sintering process. The hot agglomerate must be cooled down. The heat recovered from the sinter cooler is used to preheat the combustion air for burners in the ignition furnace. In addition to heat recovery, the system helps decreases and particulate emissions, and improves sinter productivity, yield and cold resistance. This makes a recirculated type system more efficient than a non-recirculated type.
\end{abstract}

KEYWORDS: sinter, cooler, heat balance, heat recovery

\section{Introduction}

As is known, agglomeration is a generic term used to describe the process by which a wet blend of fine ore particles, fluxes and fuel is converted into a conglomerate. The continuous improvement of iron ore agglomeration technology as a method of pre-heat preparation of furnace ores has allowed the expansion of the raw material base for the production of iron, imparting to these aggregates a character independent from particularities of the used ores (granulometry content of harmful elements, reducibility, etc.).

At the introduction of the coagulator on the cooler, its temperature is $900-1000{ }^{\circ} \mathrm{C}$, and at the outlet temperature drops to $80-100{ }^{\circ} \mathrm{C}$, making it possible to carry it further on conveyors with rubber band.

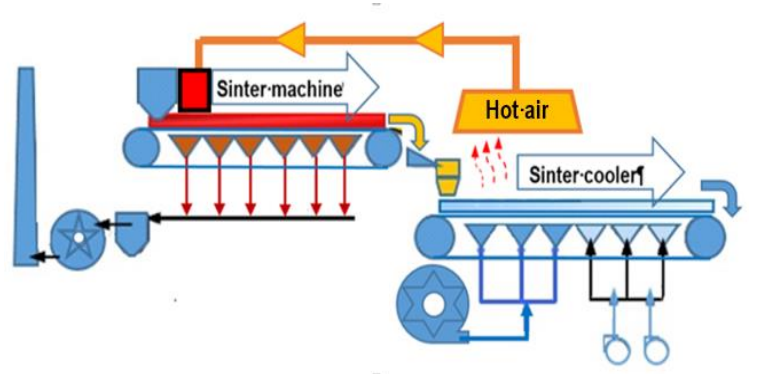

Fig. 1. Hot air oven

Recovery systems: The heat recovered from the sinter cooler is used to preheat combustion air for burners in the ignition furnace and to generate high pressure steam that can be used to generate electricity. In addition to heat recovery, the system helps reduce SOx, NOx and particulate emissions and improve sinter productivity, and cold resistance (Fig. $1)$.

Cooling the agglomerate is done by forced air injection from the bottom up, having a significant influence on the quality of the agglomerate that is obtained. All physicochemical phenomena occurring during the sintering process are conditioned by a multitude of factors that act concurrently.

\section{Objectives}

Now, the heat resulting from the cooling of the agglomerate is not recovered, being exhausted in the atmosphere (Fig. 2).

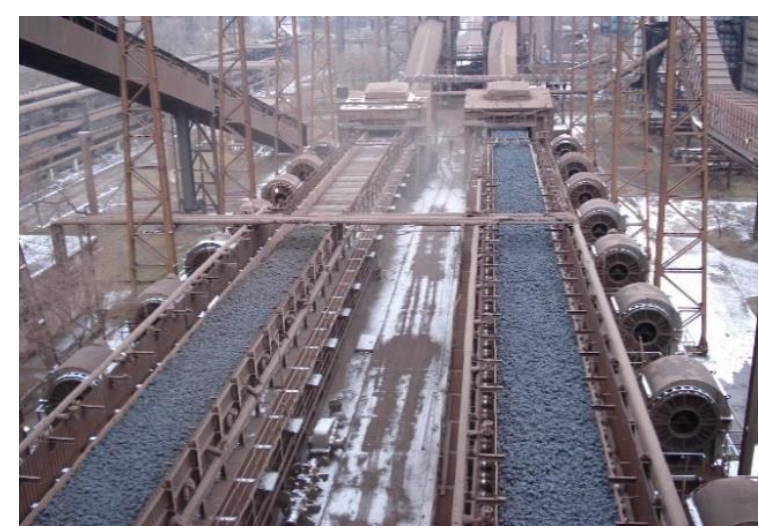

Fig. 2. Agglomerated cooler

The paper aims to determine, by thermal calculation of the amount of heat evacuated in the 
(lost) atmosphere, the graphical presentation by the Sankey diagram of the agglomeration cooler balance, as well as suggestions for using this amount of heat in order to improve the thermal efficiency of the ignition furnace of the agglomeration.

\section{Theoretical considerations}

During cooling, a series of stresses occur that are mechanical and can influence the agglomerate strength and granulation. These may be:

- thermoelastic (macro tension) that depends on the cooling conditions and can be removed by slow cooling $\left(\sigma_{t}\right)$;

- interphase (micro tension) which is caused by the difference in the coefficients of thermal expansion of the phases that make up the agglomerate $\left(\sigma_{\mathrm{i}}\right)$;

- phases that are related to polymorphic transformations $\left(\sigma_{\mathrm{f}}\right)$.

The agglomerative resistance criterion must be in the form of:

$$
R_{\text {aglo }}=\sigma_{t}+\sigma_{i}+\sigma_{f}
$$

Thermal balance calculation: Energy consumption is calculated on the basis of the thermal balance of the aggregate, which is a particular form of the principle of energy conservation. The reference items associated with the heat balance are the reference contour, the unit of time and temperature.

The reference contour (the outline) is the closed area associated with the thermal aggregate as the inputs and outputs of the thermal energy. This corresponds to the physical nature of the agglomeration cooler.

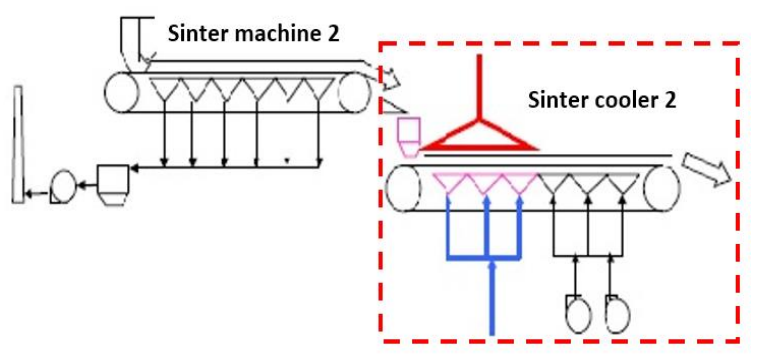

Fig. 3. Reference contour of the cooler

The reference unit (unit of time) is the time period for which the heat balance is drawn. At the agglomeration cooler the time is the operating time.

The reference temperature is the temperature at which the thermal balance components are considered. Generally, $\mathrm{t}_{0}=0{ }^{\circ} \mathrm{C}$ under normal conditions or $\mathrm{t}_{0}=15^{\circ} \mathrm{C}$ under standard conditions.
The elements of the heat balance consider all the energy carriers that enter and exit the balance sheet, being expressed by the relation:

$$
\sum \boldsymbol{Q}_{i}=\sum \boldsymbol{Q}_{\boldsymbol{e}}[\mathrm{kJ} / \mathrm{h}]
$$

where $Q_{i}$ and $Q_{e}$ represent the quantity of heat entering or leaving the balance sheet, in $\mathrm{kJ} / \mathrm{h}$.

The calculation of the heat balance on the heating cooling system allows the amount of heat generated by the cooling process, the characteristics of air-cooled cooling fans, and their dimensioning to be determined.

The quantities of heat input $\left(\sum \mathrm{Q}_{\mathrm{i}}\right)$ are calculated by summing up all the quantities of heat entering the contour:

$$
\sum Q_{i}=Q_{f a i}+Q_{a g i}+Q_{f c i}\left[\mathrm{~kJ} / \mathrm{t}_{\mathrm{ag}}\right]
$$

The physical heat of the cooling air $\left(Q_{f a i}\right)$ :

$$
Q_{f a i}=D_{a} \cdot c_{a i} \cdot t_{a i} \quad\left[\mathrm{~kJ} / \mathrm{t}_{\mathrm{ag}}\right]
$$

The physical heat of the sinter cooler inlet $\left(Q_{a g i}\right)$ :

$$
\mathrm{Q}_{\mathrm{agi}}=\mathrm{M}_{\mathrm{ag}} \cdot c_{a g i} \cdot t_{a g i}\left[\mathrm{~kJ} / \mathrm{t}_{\mathrm{ag}}\right]
$$

The heat of the cooler carts $\left(Q_{f c i}\right)$ :

$$
Q_{f c i}=m_{c r} \cdot c_{c i} \cdot t_{c i} \quad\left[\mathrm{~kJ} / \mathrm{t}_{\mathrm{ag}}\right]
$$

where

- $D_{a}$ is the flow rate of cooling air, in $\mathrm{m}^{3} \mathrm{~N} / \mathrm{t}$;

- $M_{a g}$ - the mass of the agglomerate in t;

- $m_{c r}$ - the mass of the carts on the cooler, $\mathrm{kg}$.

The quantities of heat output $\left(\sum \mathrm{Q}_{\mathrm{e}}\right)$, calculated by adding up all the heat outputs out of the contour:

$$
\sum Q_{e}=Q_{a c}+Q_{a g e}+Q_{f c e}[\mathrm{~kJ} / \mathrm{tag}]
$$
$\left(Q_{a c}\right)$ :

The amount of heat emitted by cooling gas

$$
Q_{a c}=D_{a} \cdot c_{a e} \cdot t_{a e} \quad\left[\mathrm{~kJ} / \mathrm{t}_{\mathrm{ag}}\right]
$$

The amount of heat evacuated with the sinter (Qage):

$$
Q_{\text {age }}=M_{\text {ag }} \cdot c_{\text {age }} \cdot t_{\text {age }} \quad\left[\mathrm{kJ} / \mathrm{t}_{\mathrm{ag}}\right]
$$

The heat of the cooler carts $\left(Q_{f c e}\right)$ : 


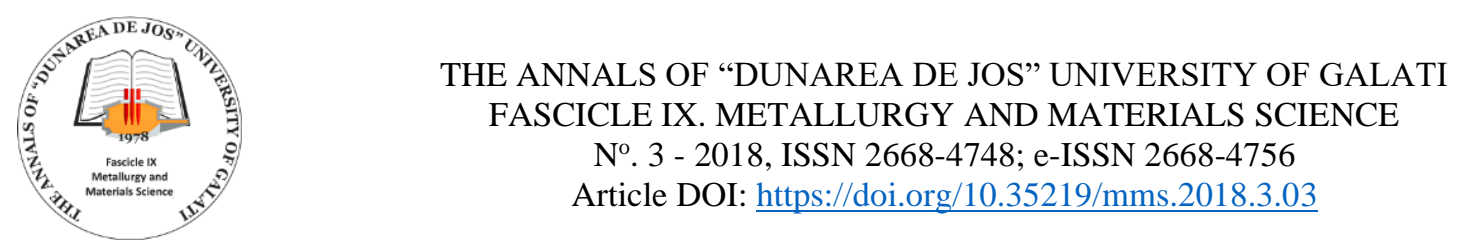

$$
Q_{f c e}=m_{c e} \cdot c_{c e} \cdot t_{c e} t_{a g e} \quad\left[\mathrm{~kJ} / \mathrm{t}_{\mathrm{ag}}\right]
$$

where:

- $D_{a}$ is the flow rate of cooling air, in $\mathrm{m}^{3} \mathrm{~N} / \mathrm{tag}$;

- $M_{a g}$ - the mass of the agglomerate, in $\mathrm{t}_{\mathrm{ag}}$;

- $m_{c e}$ - the mass of the carts on the cooler, $\mathrm{kg}$.

The cooling gas temperature, equalling the two amounts of heat or the heat input to the cooler, $\Sigma Q i$ and the amount of heat exiting the cooler $\Sigma Q e$, determines the thermal equilibrium equation. This equation allows determining the amount of heat evacuated with the cooling gases, which is unknown to the balance equation. The calculation relation is:

$$
Q_{a c}=Q_{f a i}+Q_{a g i}+Q_{f c i}-Q_{a g e}-Q_{f c e}
$$

The balance table, calculating the quantities of heat entering and leaving the balance sheet when the heat evacuated with the gases is known to the atmosphere, can be taken to the drawing up of the balance sheet. It contains both incoming heat and heat out of the value balance contour expressed in $\mathrm{kJ} / \mathrm{h}$ as well as the percentages of each amount of heat entering or leaving part of the heat input or output.

The balance sheet error, after the balance sheet is drawn up, shall be calculated based on the data in the table, the balance of errors made up of neglected items, errors in measurement and calculation that must not exceed $2.5 \%$. The calculation relation is:

$$
\varepsilon=\left(Q_{i}-Q_{e}\right) / Q_{i}
$$

The graphical representation for the clearer picture of the heat inputs and out of the coil's balance sheet is the scale-based graphical representation. In this sense, a scale is chosen at which the total amount of heat entering and out of the contour will be transposed and will be represented to the left or right of the heat quantity value (Sankey diagram).

The heat economy (E) or the amount of hot air evacuated by the heat of the agglomerate when it is cooled is:

$$
Q_{e c}=Q_{C \text { ignition }}-Q_{a c}
$$

The heat recovered from the sinter cooler is used to preheat combustion air for burners in the ignition furnace [2]. The heat economy is:

$$
E=Q_{a c} / Q_{\text {Cignition }}-100
$$

\section{Methods}

Sinter cooler features. For each sintering machine there is a cooler with a useful surface of 230 $\mathrm{m}^{2}$.

Several fans are typically used for cooling, and the cooler speed must match the demand for the grill and is determined by the speed of the grill and the bed depth. The trolleys have at the bottom a grate on which the agglomerate is laid in a layer of a maximum thickness of $800 \mathrm{~mm}$, and under the cooler air is drawn through a cooling layer, resulting from 34 fans of the existing 8 for each cooler. Fan discharge pressure is based on the agglomerate granulometry entering the cooler and is between $200 \mathrm{~mm}$ col. $\mathrm{H}_{2} \mathrm{O}$ to at least 4 fans in operation, and the total airflow is based on the amount of conglomerate on the cooler and the initial and final temperature of the cooler. This flow varies within $5000-7000 \mathrm{~m}^{3} / \mathrm{t}_{0}$.

Table 1. Characteristics of the F2 sinter cooler

\begin{tabular}{|c|c|c|c|c|c|}
\hline $\begin{array}{c}\text { Surface } \\
\text { Usable }\end{array}$ & $\begin{array}{c}\text { Height } \\
\text { Layer }\end{array}$ & $\begin{array}{c}\text { Air flow } \\
\text { Cooling }\end{array}$ & $\begin{array}{c}\text { Speed of } \\
\text { movement }\end{array}$ & \multicolumn{2}{|c|}{$\begin{array}{c}\text { Agglomerated } \\
\text { temperature }\left[{ }^{\circ} \mathrm{C}\right]\end{array}$} \\
\cline { 5 - 6 }$\left[\mathrm{m}^{2}\right]$ & {$[\mathrm{mm}]$} & {$\left[\mathrm{m}^{3} / \mathrm{t}_{\mathrm{s}}\right]$} & {$[\mathrm{m} / \mathrm{min}]$} & entry & exit \\
\hline 230 & 800 & $5 \div 7 \cdot 10^{3}$ & $2 \div 6$ & $\approx 900$ & $\approx 95$ \\
\hline
\end{tabular}

The calculation of the heat balance on the heating cooling system allows the amount of heat generated by the cooling process, the characteristics of air-cooled cooling fans, and their dimensioning to be determined.

Simplifying hypotheses. The thermal balance was based on the following assumptions:

- the layer is considered homogeneous, having an equivalent thermal conductivity and an equal initial temperature throughout the mass;

- the contact between coats placed over the cooler throughout the cooling process is perfect;

- the variation of the specific heat and thermal conductivity with temperature is considered;

- the dimensional variations (contractions) that occur during cooling are neglected;

- the inspired air flow is the same across the entire layer (loss of pressure is neglected).

Table 2. The balance table for the heat in

\begin{tabular}{|c|c|c|c|c|}
\hline \multicolumn{5}{|c|}{ THE HIEAT IN } \\
\hline No. & The heat & Eq. & $\begin{array}{c}\text { Value } \\
{\left[\mathrm{kJ} / \mathrm{t}_{\mathrm{ag}}\right]}\end{array}$ & $\begin{array}{c}\text { Percent } \\
{[\%]}\end{array}$ \\
\hline 1 & $Q_{f a i}$ & 3.1 & 433.44 & 0.92 \\
\hline 2 & $Q_{a g i}$ & 3.2 & 46388.14 & 98.46 \\
\hline 3 & $Q_{f c i}$ & 3.3 & 292.19 & 0.62 \\
\hline & Total $\left(\boldsymbol{\Sigma} \boldsymbol{Q}_{i}\right)$ & $\mathbf{3}$ & $\mathbf{4 7 1 1 3 . 7}$ & $\mathbf{1 0 0}[\boldsymbol{\%}]$ \\
\hline
\end{tabular}

The results of sinter cooler balance. Knowing the heat balance elements allows you to determine the 
amounts of heat input and output form the chassis balance. Based on these, the amount of heat evacuated with the cooling air and the improvement of the thermal efficiency can be determined.

Table 3. The balance table for the heat out

\begin{tabular}{|c|c|c|c|c|}
\hline \multicolumn{5}{|c|}{ THE HEA T OUT } \\
No. & The heat & Eq. & $\begin{array}{c}\text { Value } \\
{\left[\mathrm{kJ} / \mathrm{t}_{\mathrm{ag}}\right]}\end{array}$ & $\begin{array}{c}\text { Percent } \\
{[\%]}\end{array}$ \\
\hline 1 & $Q_{a c}$ & 4.1 & 29045.58 & 61.65 \\
\hline 2 & $Q_{a g e}$ & 4.2 & 17903.19 & 38.0 \\
\hline 3 & $Q_{f c e}$ & 4.3 & 164.92 & 0.35 \\
\hline & Total $\left(\boldsymbol{\Sigma} \mathbf{Q}_{\boldsymbol{e}}\right)$ & $\mathbf{4}$ & $\mathbf{4 7 1 1 3 . 7}$ & $\mathbf{1 0 0}[\%]$ \\
\hline
\end{tabular}

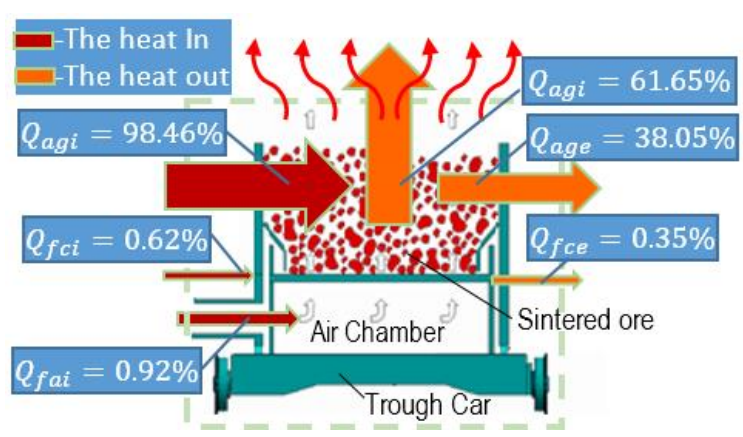

Fig. 3. Sinter cooler thermal balance

The heat economy $\left(Q_{e c}\right)$ the amount of heat exhaust air, hot air $Q_{a c}$ is:

$$
Q_{a c}=\sum Q_{e}-Q_{a g e}-Q_{c r e}=29045.58_{\left[\mathrm{kJ} / \mathrm{t}_{\mathrm{ag}}\right](15)}
$$

$$
Q_{e c}=Q_{\text {Cignition }}-Q_{a c}=134573.68\left[\mathrm{~kJ} / \mathrm{t}_{\mathrm{ag}}\right]
$$

where: $Q_{\text {Cignition }}$ is the ignition furnace from the sintering machine $\left(Q_{\text {Cignition }}=163619.271 \mathrm{~kJ} / \mathrm{t}\right)[2]$.

The heat recovered from the sinter cooler is used to preheat combustion air for burners in the ignition furnace [2]. Percent heat savings is:

$$
E=\frac{Q_{a c}}{Q_{C \text { ignition }}} 100=\frac{29045.58}{163619.27} 100=17.75[\%]
$$

\section{Conclusions}

Depending on the high exhaust gas temperature, only 30 to $40 \%$ of the cooling air of a linear cooler can be used to recover heat.

Only the final part of the sintering section and the primary part of the cooling section where the gas is at a temperature of $300{ }^{\circ} \mathrm{C}$ or higher is thus available.

By recovering the heat from the hot air from the agglomeration cooler an amount of heat can be obtained that can be used in the agitating furnace's furnace to achieve a fuel economy of $\mathrm{E}=17.75 \%$.

\section{References}

[1]. ***, Documentation ArcelorMittal Galati.

[2]. Vasiliu A., Study on the use of oxygen-enriched combustion air at the ignition initiator furnace from the agglomeration machine, The Annals of "Dunarea de Jos" University of Galati, Fascicle IX, no. 4, ISSN 1453-083X, 2017. 